\title{
The drag effect of air bubbles on triple junction migration of pure ice
}

\author{
Pastor Ignacio Achával ${ }^{1 *}$, Carlos Leonardo Di Prinzio ${ }^{1,2}$ \\ ${ }^{1}$ FAMAF (Facultad de Matemática, Astronomía, Física y Computación). Universidad \\ Nacional de Córdoba. Medina Allende y Haya de la Torre. (5000) Ciudad Universitaria. \\ Córdoba, Argentina \\ ${ }^{2}$ IFEG-CONICET (Instituto de Física "Enrique Gaviola") Universidad Nacional de \\ Córdoba. Medina Allende y Haya de la Torre. (5000) Ciudad Universitaria. Córdoba, \\ Argentina
}

\begin{abstract}
The migration of a grain triple junction was studied on ice pure samples with bubbles at $-2^{\circ} \mathrm{C}$ for almost $3 \mathrm{~h}$. This work studies the interaction between Grain Boundary (GB) and bubbles. The evolution of the triple junction was recorded from successive photographs obtained from a LEICA ${ }^{\circledR}$ optical microscope. Simultaneously, numerical simulations of grain triple junction with mobile bubbles were carried out using Monte Carlo method with the following conditions: The bubbles in the bulk were kept immobile and those in the GB were allowed to move. In addition, mobile bubbles were forced to stay inside the GB. The simulations show that bubbles slow down the movement of the GB and of the triple junction. What's more, the simulated triple junction obtained fits very well the experimental triple junction geometry, and the GB diffusivity values obtained coincide with those measured experimentally at the same temperature and reported by other authors. Finally, the drag effect of the mobile bubbles on the GB migration was verified.
\end{abstract}

Key words: ice, grain boundary, tricrystal, surface diffusion, Monte Carlo

DOI: $10.5817 / \mathrm{CPR} 2021-1-7$

\section{Introduction}

It is already known that polar ice has soluble impurities, solid impurities, bubbles and other types of contaminants (Durand et al. 2006, Krachler et al. 2005). These bubbles contain the air that existed on Earth thousands of years ago (Severinghaus et al. 1998). Paleoclimatologists use the bubbles to study changes in the com- position of the air in past times and relate them to current atmospheric changes (Guillet et al. 2021, Patterson and Saltzman 2021, Seltzer et al. 2021, Severinghaus and Brook 1999).

Ice bubbles originated when atmospheric air was trapped by snow deposited on the polar ice cap. They were trans-

Received October 14, 2020, accepted June 20, 2021.

*Corresponding author: P. I. Achával <pachaval@famaf.unc.edu.ar> Acknowledgements: This work was possible thanks to the collaboration of José Barcelona. This research project was financially supported by SeCyT (Secretaria de Ciencia y Técnica de la UNC) and CONICET (Consejo Nacional de Ciencia y Tecnología de Argentina). 
ported to the depths of polar ice due to the accumulation of snow on the surface and their size was slowly reduced (Gow 1969). In the first 100 meters of depth, the ice is called firn and has a lot of air in channels of different sizes and shapes. Due to the pressure of the ice mass, from the depth of 100 meters on, the air is transformed into bubbles. This phenomenon is called closeoff (Gow 1969).

Polar ice is formed by ice crystals (or grains) that increase in size over time and depth (Alley et al. 1986a, b). The grain size depends on the number of impurities, the temperature and the number, size and shape of the bubbles formed inside the ice mass (Arena et al. 1997, Azuma et al. 2012, Nasello et al. 1992a).

Some studies (Arnaud et al. 1998, 2000; Roessiger et al. 2014) have been conducted in order to determine how bubbles move in the ice and how they affect grain growth in polar layers.

Recently, Roessiger et al. (2014) studied, by numerical simulation, the effect of bubbles on the growth of grain in ice. They found that bubbles reduce grain growth (CG). Arena et al. (1997) and Nasello et al. (1992a) studied laboratory ice samples with and without bubbles. They found that bubbles change the extrinsic mobility of grain boundaries (GB). The bubbles at the grain boundaries as well as those out-

\section{Material and Methods}

Experiments were conducted using a tricrystalline ice sample obtained according to the method proposed by Nasello and Di Prinzio (2011). The surface of the tricrystalline sample was polished by a microtome (Fig. 1a) and immediately immersed in a cell with silicone oil that was hermetically sealed, to avoid evaporation or gaseous diffusion, as shown in Fig. 1b. After polishing the ice surface, the surface side the grain boundaries are involved in slowing down GB movement. As the GB moves, the bubbles outside the GB (inside the grain) can be incorporated into the GB. Therefore, these bubbles should affect the movement of the GB.

The size and distribution of ice crystals as well as the size and distribution of bubbles were obtained from plastic replicas (Arena et al. 1997, Azuma et al. 2012, Nasello et al. 1992a). This method of the plastic replicas consists of polishing the surface of the ice and, after a few minutes, depositing a layer of plastic (solution of $5 \%$ in weight of Fomvar in 1-2 dichloroethane) on it. The plastic, once dry, produces a copy of the grain boundaries and the bubbles on the polished surface. The evolution of the average grain size and the bubbles' sizes for a regular interval of time can be studied by this method. Therefore, it can be inferred that following the evolution of the same bubble or crystal is impossible since the surface must be polished again for each observation destroying the previous information.

Experimental data on how air bubble interacts with the GB and affects its migration in ice are rather scarse (Arena et al. 1997, Azuma et al. 2012, Nasello et al. 1992a). In this paper, a study on the migration of a triple grain boundary in pure ice samples at $-2^{\circ} \mathrm{C}$ with bubbles is presented.

scratches were less than $0.1 \mu \mathrm{m}$.

The cell with the tricrystalline sample was placed into a box where the temperature was controlled as specified below). The box was placed on the plate of a LEICA ${ }^{\circledR}$ microscope and, with the use of a LAUDA ${ }^{\circledR}$ cooling system, the circulation of Ethylene glycol kept the temperature in the cell constant at $-2^{\circ} \mathrm{C}$. 

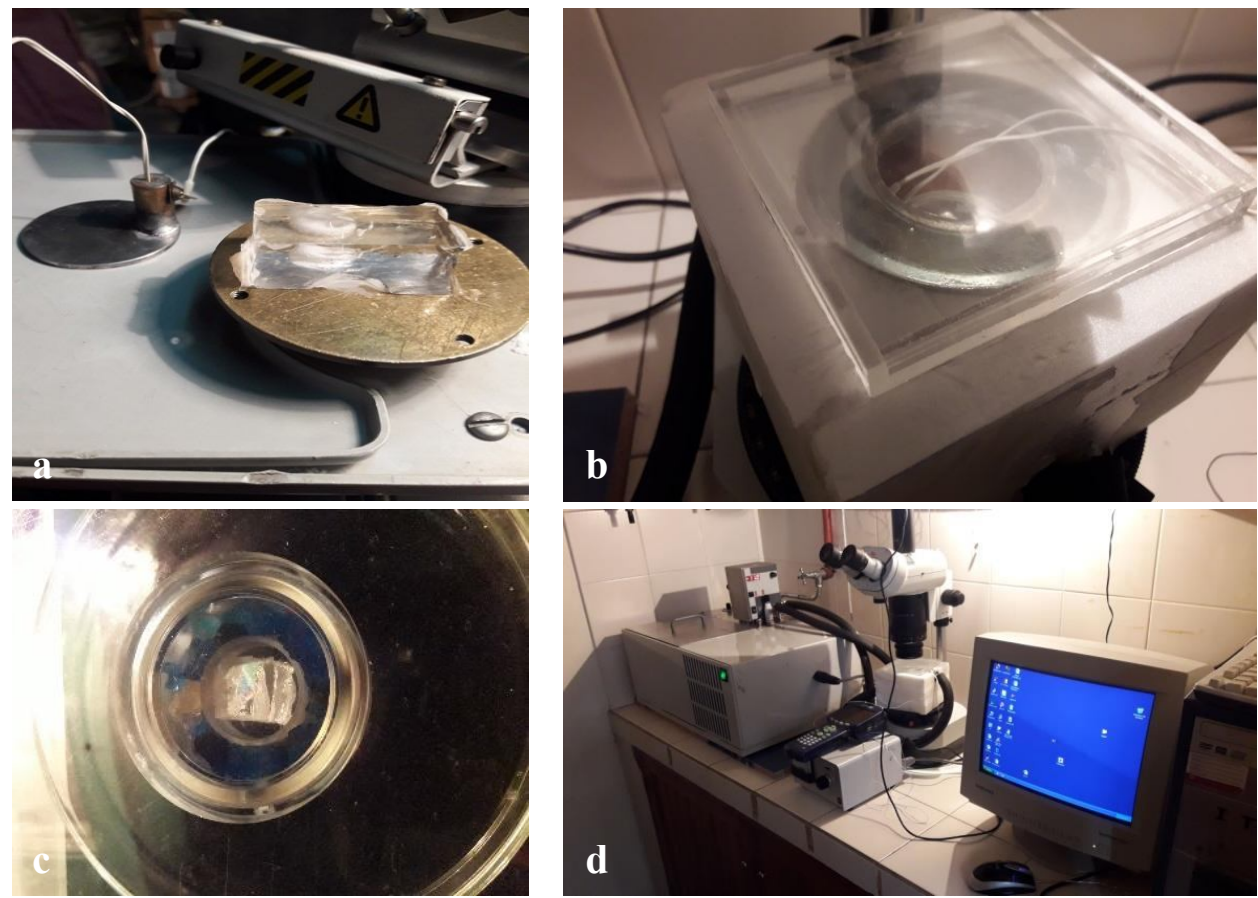

Fig. 1. a) Ice sample on the microtome plate. b) Transparent cell in the cold box. c) Ice sample in a transparent cell with silicon oil. d) Experimental set-up consists of a cooling system with hoses that reach the cold box located on the microscope plate. A personal computer records the digital images obtained by a video-camera laid at the top of the microscope while a datalogger measures the temperature inside and outside the cold box.

Fig. 2 shows a sequence of the triple junction reached at $0 \mathrm{~h}, 0.5 \mathrm{~h}, 1 \mathrm{~h}, 1.5 \mathrm{~h}$ and $2.5 \mathrm{~h}$. The images were rotated, cropped and digitally processed with the ImageJ $\mathbb{R}$ software. These modifications did not affect the position of the GBs or the bubbles.

From this sequence, it was seen that the bubbles in the bulk remained immobile while the bubbles in the GB moved. In general, the bubbles in the GB accompany the movement of the GB. It was not observed that they leave the GB. From the photos, it was seen that the large bubbles at the bottom of the photos are traversed by the GB.

\section{Numerical Simulation with Monte Carlo (Mc) Method}

The simulation of three-dimensional (3D) tricrystal growth with MC uses the same algorithms as those used in twodimensional (2D) (Anderson et al. 1984, Choudhury and Jayaganthan 2008, Srolovitz et al. 1983, 1984) and 3D (Achával and Di Prinzio 2018, Choudhury and Jayaganthan 2008, Di Prinzio et al. 2013) polycrystalline samples.

Initially, a tricrystal is created within a matrix of $Q=N_{x} \times N_{y} \times N_{z}$ where $N_{x}, N_{y}$ and $N_{z}$ represent the number of sites on the direction $\boldsymbol{x}, \boldsymbol{y}$ and $\boldsymbol{z}$, respectively. Each site $\boldsymbol{i}$ has a unique position $\left(\boldsymbol{x}_{\boldsymbol{i}}, \boldsymbol{y}_{\boldsymbol{i}}, \boldsymbol{z}_{\boldsymbol{i}}\right)$ and orientation $\left(\boldsymbol{S}_{\boldsymbol{i}}\right)$. 

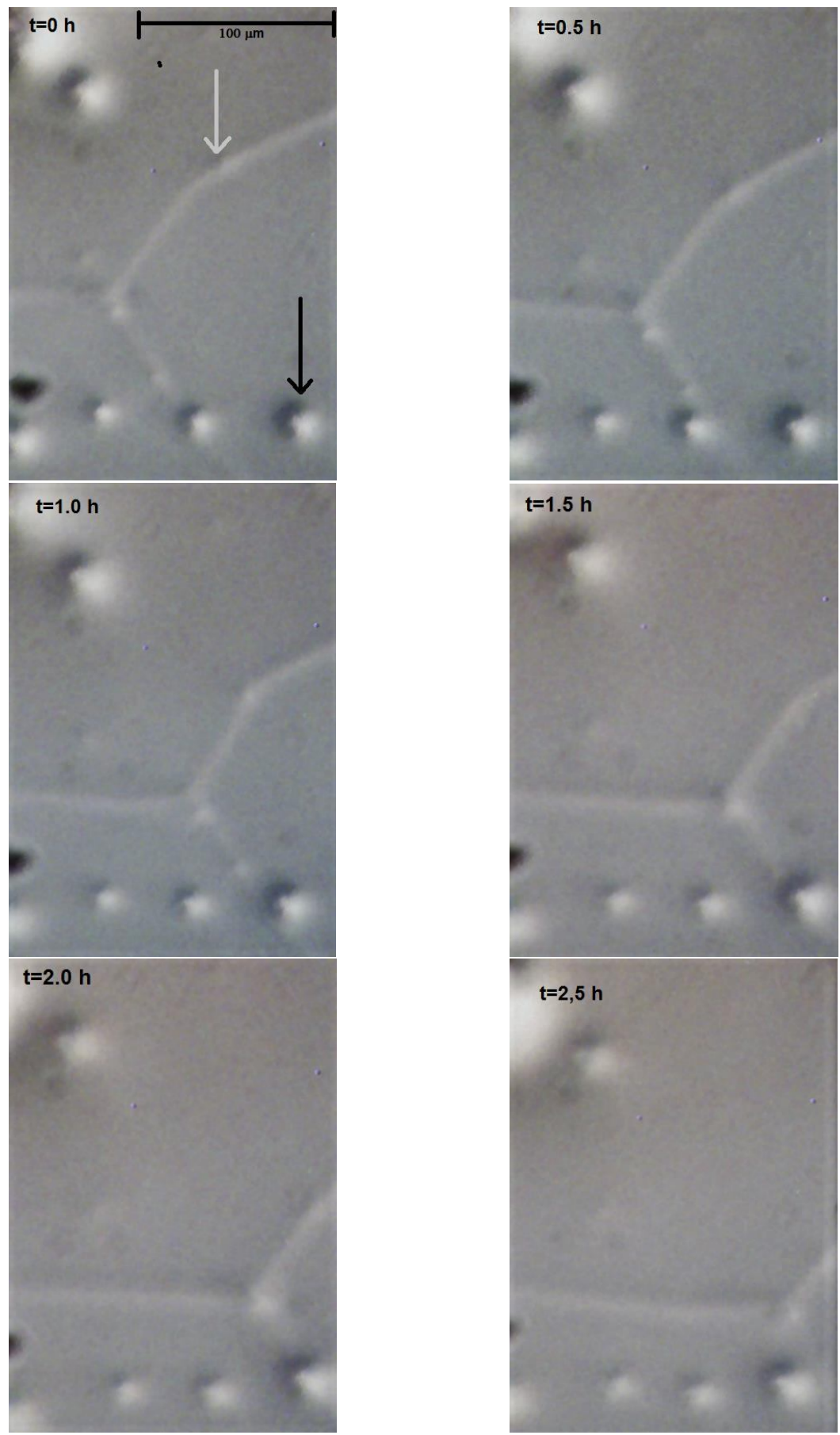

Fig. 2. Photo sequence of the triple junction after $0 \mathrm{~h}, 0.5 \mathrm{~h}, 1 \mathrm{~h}, 1.5 \mathrm{~h}$ and $2.5 \mathrm{~h}$. - The grey arrow indicates small bubbles that migrate with the grain boundaries (GB) and do not leave it. The black arrow indicates large bubbles in the bulk; they remain stationary and do not accompany the GB in its movement. 
In the Monte Carlo simulation, the GB of the experimental tricrystals had to be represented numerically by mathematical curves. It was difficult to choose an initial configuration of the tricrystal that represents the original shape of the GB.

$\mathbf{a}$

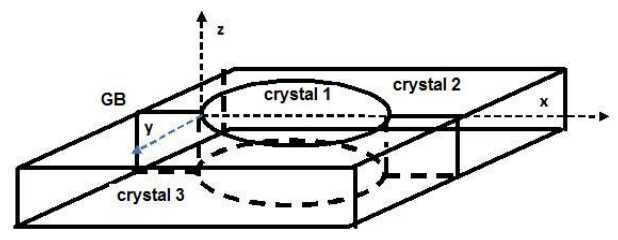

Several mathematical curves were tested but ellipses best fitted the grain boundaries geometry of the tricrystralline sample.

In this model, crystals 1,2 and 3 have orientation $\boldsymbol{S}_{\boldsymbol{i}}=1,2$ and 3, respectively, and bubbles $\boldsymbol{S}_{\boldsymbol{i}}=0$ (see Fig. 3).

b

A

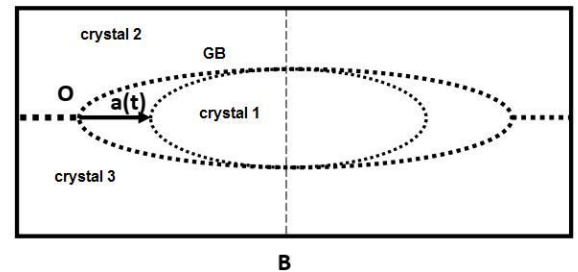

Fig. 3. a) 3D tricrystal simulates the ice sample. The $x-y-z$ coordinate system is shown. b) $2 D$ view of the $3 \mathrm{D}$ simulated tricrystal. Two stages of migration are presented, the original position of the triple $\mathrm{O}$ junction and its displacement $\boldsymbol{a}(\boldsymbol{t})$.

The algorithm followed these steps for sites belonging to one of the crystals:

a) The total energy of the tricrystal $\boldsymbol{W}$ is given by:

$$
W=\frac{1}{2} \sum_{i=1}^{Q} \sum_{j=1}^{V} J\left(1-\delta_{\text {SiSj }}\right) \quad \text { Eqn. } 1
$$

with $\boldsymbol{S}_{\boldsymbol{i}}$ and $\boldsymbol{S}_{\boldsymbol{j}}$ orientations of network sites $\boldsymbol{i}$ and $\boldsymbol{j}$ respectively, $\boldsymbol{J}$ energy of interaction between sites, $\boldsymbol{V}$ number of neighbors to site $\boldsymbol{i}$, and $\boldsymbol{\delta}$ delta function of Kronecker. An $\boldsymbol{i}$ site is chosen at random, and it belongs to a grain $\boldsymbol{i}$ with orientation $\boldsymbol{S}_{\boldsymbol{i}}$. Equation (1) calculates the energy around the $\boldsymbol{i}$ site:

$$
W_{i}^{i n}=\sum_{j=1}^{V} J\left(1-\delta_{\mathrm{SiSj}}\right)
$$

Eqn. 2

where the superscript in means initial stage.

b) The orientation of site $\boldsymbol{i}\left(\boldsymbol{S}_{\boldsymbol{i}}\right)$ is then replaced by an orientation $\left(\boldsymbol{S}_{\boldsymbol{j}}\right)$ of site $\boldsymbol{j}$ obtained randomly from its grain neighbors.

c) The energy of $\boldsymbol{W}_{\boldsymbol{i}}^{\boldsymbol{i}} \quad$ site $\boldsymbol{i}$ is recalculated where the superscript $\boldsymbol{f} \boldsymbol{i}$ means final stage of energy.

d) Then, the difference in energies is calculated:

$$
\Delta W_{i}=W_{i}^{f i}-W_{i}^{i n}
$$

\section{Eqn. 3}

If equation (3) is negative or zero, the change occurs permanently; and if it is positive, a probability $P$ given by:

$$
P=e^{\frac{-\Delta W_{i}}{\mathrm{kT}}}
$$

Eqn. 4

where $\boldsymbol{k}$ is Boltzman's constant and $\boldsymbol{T}$ is the temperature of the tricrystal. 
To allow the system to produce changes by thermal activation, a random number $\boldsymbol{M}$ between 0 and 1 is chosen and compared with $\boldsymbol{P}$. If $\boldsymbol{P}$ is larger than $\boldsymbol{M}$, then the change of $\boldsymbol{S}_{\boldsymbol{i}}$ by $\boldsymbol{S}_{\boldsymbol{j}}$ is made; otherwise, it is not.

The mobile bubbles were ruled by the following steps:

a) The mobile bubbles were represented with the orientation $\boldsymbol{S}_{\boldsymbol{i}}=0$ and their concentration remained fixed throughout the simulation (Achával and Di Prinzio 2018, Di Prinzio et al. 2013). The initial positions were in accordance with the initial photo of the ice tricrystal sample. Bubbles were represented by cubes of the same size, even though in the original sample they were not.

b) A site $\boldsymbol{w}$ was chosen at random from the sample and verified to have $\boldsymbol{S}_{\boldsymbol{i}}=0$ (bubble site).

c) In order to move the bubbles, the site chosen at random, $\boldsymbol{w}$ had to belong to the geometric center of the bubble.

d) The bubbles within a grain $(\mathrm{G})$ and in a sample border were not be moved, contrastingly to the bubbles in the GB.

e) Not all bubbles within the GB were moved in an MC Step (MCS). When a bubble in the GB was chosen, a random number $\boldsymbol{H}$ was calculated. If that number was lower than probability $\boldsymbol{P}$, given by equation (4) with $\boldsymbol{\Delta} \boldsymbol{W}=\mathbf{1 , 6 k T}$, then the chosen bubble was moved.

f) A bubble had 26 neighbors that determined 26 possible directions of movement. The direction of movement of the bubble was chosen randomly from these directions.

g) If the chosen direction moved the bubble out of the GB or towards the sample border, the direction was discarded and a new one chosen.

h) The direction chosen for the bubble movement had to keep the bubble in the GB, centered on it (Fig. 4).

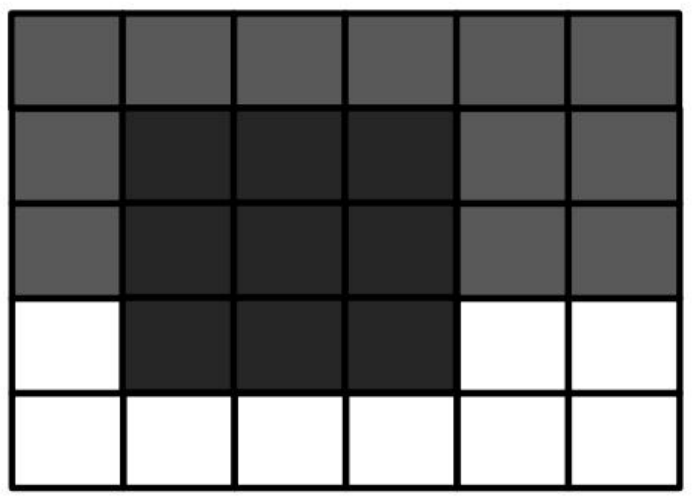

Fig. 4. 2D projection of a mobile bubble centered on the grain boundary (GB, black) between an upper grain (gray) and a lower grain (white). Each cube is a boxel (pixel ${ }^{3}$ ). 


\section{Model Parameter Settings}

The 3D grain growth numerical Simulation with Monte Carlo method was used in a $200 \times 100 \times 7$ pixel $^{3}$ sample with mobile particles and uniform GB energy. It was imposed to all sites that they could not move in the $\mathrm{z}$-direction. In this way, a 2D simulation was obtained. This was done because the pictures obtained from the real samples were in 2D and showed a wide focal plane where bubbles could be seen in focus or out of focus. The $\boldsymbol{J}$ value used was $\boldsymbol{k} \boldsymbol{T}$ (Hassold and Srolovitz 1995). Each bubble was demonstrated as a cubic

$\mathbf{a}$

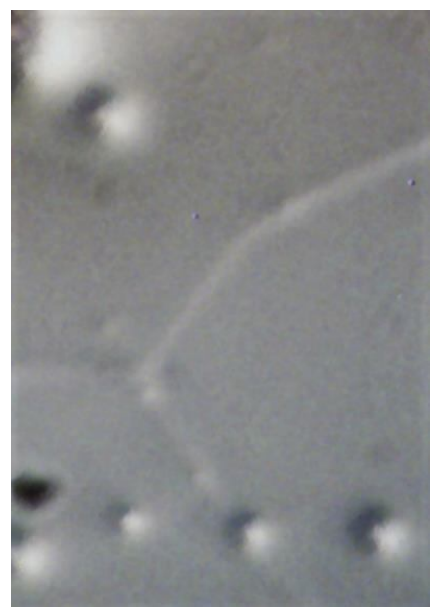

object and its sides were of 3 pixels (the distance unit in the sample was called pixel).

A tricrystal with bubbles (WB) and a tricrystal without bubbles (NB) were simulated in such a way that their configuration coincided with that of the original ice tricrystal (Fig. 5). In each step and for each tricrystal, the values of $\boldsymbol{a}(\boldsymbol{t})$ were recorded. Nevertheless, the amount of particles in the GB was recorded only for the simulation of the tricrystal WB.

b

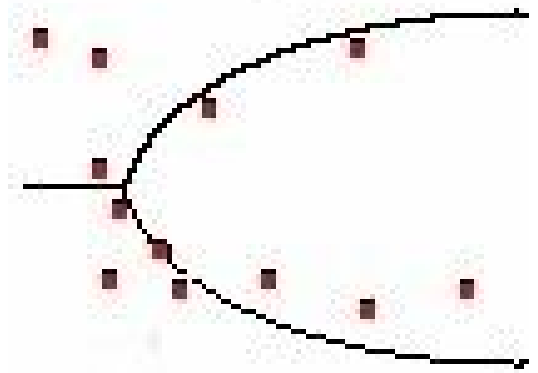

Fig. 5. a) Image of the real tricrystal. b) Left half of the simulated tricrystal with bubbles (WB) shown in Fig. 3b. The rectangle area represents the visible area of the real ice tricrystal shown in a).

Fig. 6 shows snapshots of the simulation of the tricrystal WB evolution at a given Monte Carlo Step (MCS).

In order to be able to compare the simulated values with the experimental values, MCS and pixel must be dimensioned as time and distances, respectively. This required previous simulation of the evolution of a circular bicrystal and to study its GB migration. The radius $(\boldsymbol{R})$ of the circular bicrystal changes with time $(\boldsymbol{t})$ according to the following theoretical equation:

$$
\boldsymbol{R}^{2}=\mathbf{2} \boldsymbol{M} \boldsymbol{\gamma t}+\boldsymbol{R}_{\mathbf{0}}^{2} \quad \text { Eqn. } 5
$$

where $\boldsymbol{R}_{\mathbf{0}}=\mathbf{4 0}$ pixel is the initial radius, and $\boldsymbol{M}$ and $\boldsymbol{\gamma}$ are, respectively, mobility and GB energy (Sutton and Balluffi 1995). 

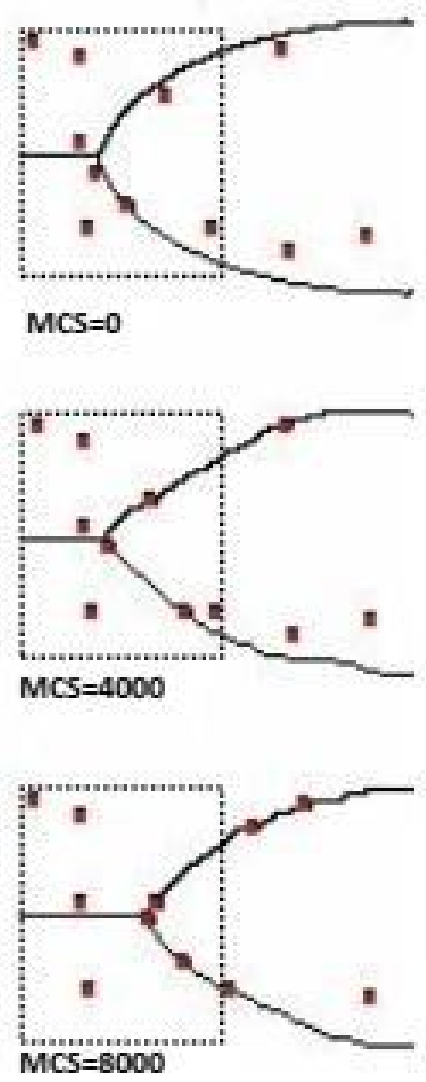

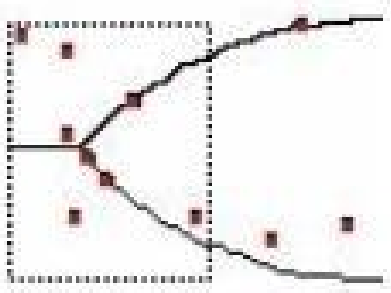

MCS $=2000$
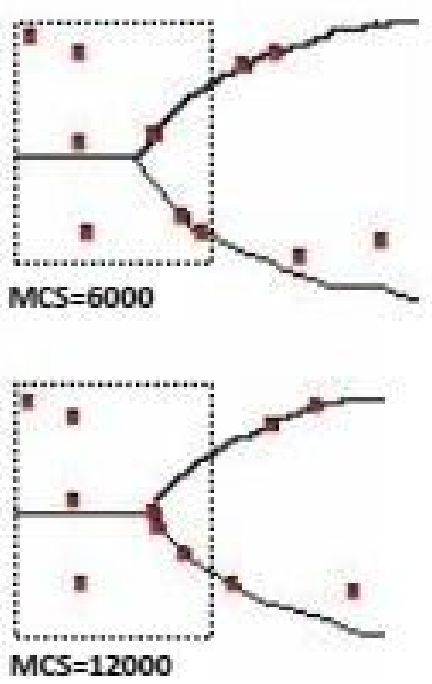

Fig. 6. Evolution of a 2D tricrystal WB at 0, 2000, 4000, 6000, 8000 and 12000 MCS. The rectangle area represents the visible area of the real ice tricrystal shown in Fig. 2.

The radius of a circular bicrystal (Choudhury and Jayaganthan 2008) in a Monte Carlo simulation also satisfies the same lineal function:

$$
\boldsymbol{R}^{2}=\boldsymbol{s}(\boldsymbol{M C S})+\boldsymbol{R}_{\mathbf{0}}^{2} \quad \text { Eqn. } 6
$$

From the simulation of circular bicrystal, the result was that the square of the sphere radius $\left(\boldsymbol{R}^{2}\right)$ decreases lineally with MCS (Fig. 7). The slope of that linear relationship $\boldsymbol{s}$ (Eqn. 6) was evaluated:

$$
\begin{array}{ll}
\boldsymbol{s}=\mathbf{0 . 2 2} \frac{\text { pixel }^{2}}{\text { MCS }} \quad \text { Eqn. } 7
\end{array}
$$

Furthermore, it is known that the square of the bicrystal radius decreases with time with a slope $\boldsymbol{s}$ equal to $\mathbf{2 M} \boldsymbol{\gamma}(E q n$. 5). Therefore, it must be met:

$$
\frac{\text { pixel }^{2}}{M C S}=9.09 \mathrm{Mr}
$$

Eqn. 8 
The diameter of the bubbles in the simulation was $\mathbf{3}$ pixels and the average diameter of the bubbles in the ice samples was $\mathbf{1 0} \boldsymbol{\mu m}$. Therefore, the relationship between the two lengths is:

$$
1 \text { pixel }=3.3 \mu \mathrm{m}
$$

From Equations (8) and (9), one $\boldsymbol{M C S}$ is:

$$
M C S=1.210^{-8} \frac{m m^{2}}{M \gamma}
$$

A value of $M \gamma \approx 1,610^{-8} \frac{\mathrm{cm}^{2}}{\mathrm{~s}}$ was chosen to fit the tricrystal WB coordinate $\boldsymbol{a}(\boldsymbol{t})$ with the one obtained from the measurement on the real pictures, and it turned out that $M C S \approx 210^{-4} \mathrm{~h}$.

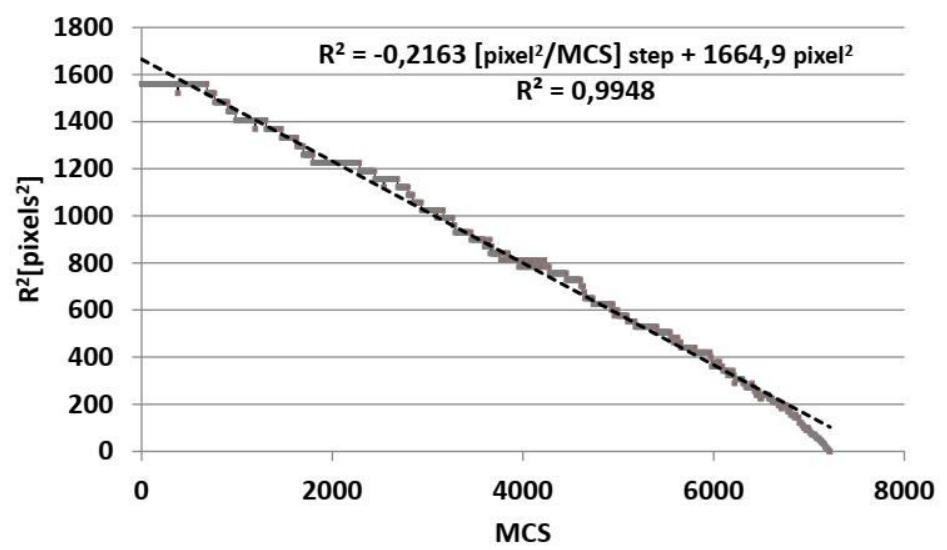

Fig. 7. Evolution of $\mathrm{R}^{2}$ vs MCS for a circular bicristal with $\mathrm{R}_{0}=40$ pixels.

In Fig. 8, the coordinate $\boldsymbol{a}(\boldsymbol{t})$ is presented for experimental samples, WB and NB simulated samples. A very good correlation between WB simulated and experimental $a(t)$ values indicates that the choice of the tricrystal configuration used in the simulation was correct and that the mechanism of interaction between the bubble and the GB was adequate. From figure 6, it follows that the final configuration of tricrystal WB at 12000 MCS represents, approximately, the picture of the real tricrystal at $2.5 \mathrm{~h}$.

The tricrystal NB values of $\boldsymbol{a}(\boldsymbol{t})$ were also presented in Fig. 8. During the simulations it was verified that the $\boldsymbol{a}(\boldsymbol{t})$ value of the tricrystal NB is greater than that of the tricrystal WB. This result shows that, in pure ice, the bubbles slow down the GB and triple junctions migrations.

The value of $\boldsymbol{M} \boldsymbol{\gamma}$ chosen for the fitting was similar to $\overline{M \gamma} \approx 1,110^{-8} \frac{\mathrm{cm}^{2}}{\mathrm{~s}}$ at $-2^{\circ} \mathrm{C}$ in pure bicrystalline ice samples studied by Nasello et al. (1992b). This result is very important because the pure ice sample used in this experiment was made with the same laboratory conditions as those of Nasello et al. (1992b) and Di Prinzio and Nasello (1997). 


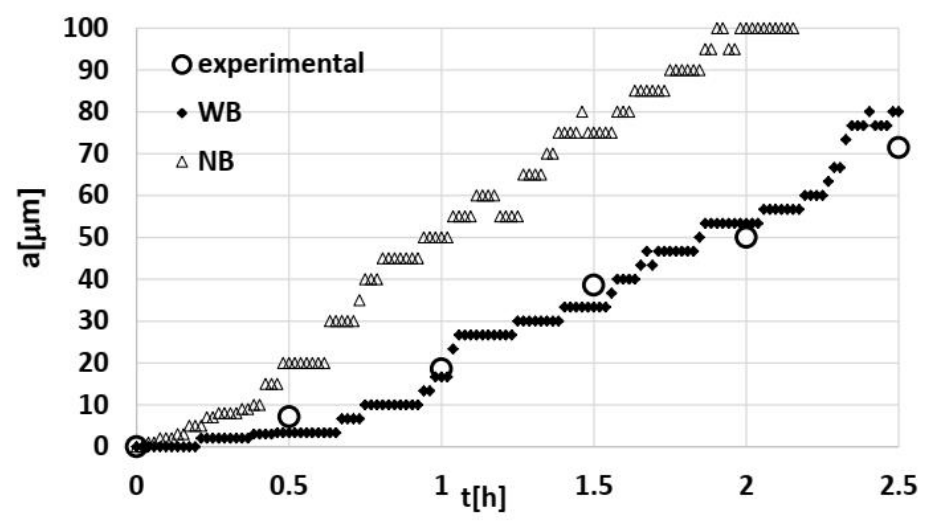

Fig. 8. Evolution of coordinate $\boldsymbol{a}(\boldsymbol{t})$ for the simulated tricrystal with bubbles (WB) and without bubbles (NB), and for the real ice tricrystal with bubbles.

\section{Conclusions}

The type of study carried out in this work is very scarce in ice research and the technique used to study grain growth and GB migration in ice is really novel (Arena et al. 1997, Di Prinzio and Nasello 1997, Gow 1969, Nasello et al. 1992a, b; Nasello and Di Prinzio 2011). In this work, the migration of an ice triple junction with bubbles over 2.5 hours was observed. To reproduce the experimental observations, the bubbles were kept immobile in the bulk and allowed to move in the GB. The mechanisms of interaction of the GB with the bubbles were analyzed, and some of the characteristics of these interactions were incorporated into a computer model using the Monte Carlo Method. In addition, the mobile bubbles were forced to accompany the GB at all times. This was based on photographs taken by Gow (1969). In the present work, the numerical simulation describes very well the real behavior of the tricrystalline samples although the behavior of the bubbles is not fully represented. The unique physical parameter of the mod- el $M \gamma$ was similar to the $\overline{M \gamma}$ at $-2^{\circ} \mathrm{C}$ in ice samples reported in the literature. On the other hand, it was showed that bubbles slowed down the movement of the GB and of the triple junctions. This result could be very important in decreasing the grain size in polar ice between $0 \mathrm{~m}$ to $100 \mathrm{~m}$ which is observed in the ice cores GISP2 (Gow et al. 1997), GRIP (Castelnau et al.1996) and Vostok (Morland 2009) among others. Similar results were obtained by Roessiger et al. (2014) in their numerical simulation, and by Arena et al. (1997) and Nasello et al. (1992a) in laboratory ice samples with and without bubbles. In future works, the algorithm might be improved so that it describes other physical variables of natural ice, such as the different sizes of the mobile bubbles. It could also include physical effects observed in polar ice such as grain deformation due to pressure, grain rotation, and anisotropy of BG energy and mobility (Alley et al. 1986a, b; Castelnau et al. 1996). 


\section{References}

AchÁval, P. I., Di PRINZio, C. L. (2018): Three-dimensional grain growth with mobile particles using Monte Carlo method. Matéria (Rio de Janeiro), 23(2). doi: 10.1590/s1517707620180002.0443

Alley, R. B., Perepezko, J. H. and Bentley, C. R. (1986a): Grain Growth in polar ice: I. Theory. Journal of Glaciology, 32(112): 415-424. doi: 10.3189/S0022143000012120

Alley, R. B., Perepezko, J. H. and Bentley, C. R. (1986b): Grain Growth in polar ice: II. Application. Journal of Glaciology, 32(112): 425-433. doi: 10.3189/S0022143000012132

Anderson, M. P., Srolovitz, D. J., GReSt, G. S. and SAHNi, P. S. (1984): Computer simulation of grain growth - I. Kinetics. Acta Metallurgica, 32(5): 783-791. doi: 10.1016/0001-6160(84) 90151-2

Arena, L., Nasello, O. B. and Levi, L. (1997): Effect of bubbles on grain growth in ice. The Journal of Physical Chemistry B, 101(32): 6109-6112. doi: 10.1021/jp9632394

Arnaud, L., Barnola, J. M. and Duval, P. (2000): Physical modeling of the densification of snow/firn and ice in the upper part of polar ice sheets. In: T. Hondoh (ed.): Physics of Ice Core Records. Hokkaido University Press, Sapporo, pp. 285-305.

ARnaud, L., GAY, M., BARnOla, J. M. and Duval, P. (1998): Imaging of firn and bubbly ice in coaxial reflected light: a new technique for the characterization of these porous media. Journal of Glaciology, 44(147): 326-332. doi: 10.3189/S0022143000002653

Azuma, N., Miyakoshi, T., Yokoyama, S. and Takata, M. (2012): Impeding effect of air bubbles on normal grain growth of ice. Journal of Structural Geology, 42: 184-193. doi: 10.1016/j.jsg.2012.05.005

Castelnau, O., Thorsteinsson, T., Kipfstuhl, J., Duval, P. and Canova, G. R. (1996): Modelling fabric development along the GRIP ice core, central Greenland. Annals of Glaciology, 23: 194-201. doi: 10.3189/S0260305500013446

Choudhury, S., Jayaganthan, R. (2008): Monte Carlo simulation of grain growth in 2D and 3D bicrystals with mobile and immobile impurities. Materials Chemistry and Physics, 109(2-3): 325-333. doi: 10.1016/j.matchemphys.2007.11.037

Di Prinzio, C. L., Druetta, E. and Nasello, O. B. (2013): More about Zener drag studies with Monte Carlo simulations. Modelling and Simulation in Materials Science and Engineering, 21(2): 025007, pp. 1-8. doi: 10.1088/0965-0393/21/2/025007

Di Prinzio, C. L., NASEllo, O. B. (1997): Study of grain boundary motion in ice bicrystals. The Journal of Physical Chemistry B, 101(39): 7687-7690. doi: 10.1021/jp963258d

Durand, G., Weiss, J., Lipenkov, V., Barnola, J. M., Krinner, G., Parrenin, F., Delmonte, B., Ritz, C., Duval, P., Rothlisberger, R. and Bigler, M. (2006): Effect of impurities on grain growth in cold ice sheets. Journal of Geophysical Research, 111: F01015, pp. 1-18. doi: 10.1029/2005JF000320

Gow, A. J. (1969): On the rate of growth of grains and crystals in south polar firn. Journal of Glaciology, 8(53): 241-252. doi: 10.3189/S0022143000031233

Gow, A. J., Meese, D. A., Alley, R. B., FitzPatrick, J. J., Anandakrishnan, S., Woods, G. A., and EldER, B. C. (1997): Physical and structural properties of the Greenland Ice Sheet Project 2 ice core: A review. Journal of Geophysical Research: Oceans, 102(C12): 26559-26575.

Guillet, G., Preunkert, S., Ravanel, L., Montagnat, M. and Friedrich, R. (2021): Investigation of a cold-based ice apron on a high-mountain permafrost rock wall using ice texture analysis and micro $-{ }^{14} \mathrm{C}$ dating: A case study of the Triangle du Tacul ice apron (Mont Blanc massif, France). Journal of Glaciology, 1-8. doi: 10.1017/jog.2021.65

Krachler, M., Zheng, J., Koerner, R., Zdanowicz, C., Fisher, D. and ShOtyK, W. (2005): Increasing atmospheric antimony contamination in the northern hemisphere: snow and ice evidence from Devon Island, Arctic Canada. Journal of Environmental Monitoring, 7(12): 1169-1176. doi: 10.1039/B509373B

Morland, L.W. (2009): Age-depth correlation, grain growth and dislocation-density evolution, for three ice cores. Journal of Glaciology, 55(190): 345-352. doi: 10.3189/002214309788608 723 
Nasello, O., Arena, L. E. and Levi, L. (1992a): Grain growth in pure ice, effects of mobile bubbles. In: N. Maeno and T. Hondoh (eds.): Physics and Chemistry of Ice. Hokkaido University Press, Sapporo, pp. 422-427.

Nasello, O., Di PRinZio, C. L. and Levi, L. (1992b): Grain boundary migration in bicrystals of ice. In: N. Maeno and T. Hondoh (eds.): Physics and Chemistry of Ice. Hokkaido University Press, Sapporo, pp. 206-211.

Nasello, O. B., Di Prinzio, C. L. (2011): Anomalus effects of hydrostatic pressure on ice surface self-diffusion. Surface Science, 605(11-12): 1103-1105. doi: 10.1016/j.susc.2011.03.014

Patterson, J. D., Saltzman, E. S. (2021): Diffusivity and solubility of $\mathrm{H}_{2}$ in ice Ih: Implications for the behavior of $\mathrm{H}_{2}$ in polar ice. Journal of Geophysical Research: Atmospheres, 126, e2020JD033840. doi: 10.1029/2020JD033840

RoEssiger, J., Bons, P. D. and FARIA, S. H. (2014): Influence of bubbles on grain growth in ice. Journal of Structural Geology, 61: 123-132. doi: 10.1016/j.jsg.2012.11.003

Seltzer, A. M., NG, J., Aeschbach, W., Kipfer, R., Kulongoski, J. T., Severinghaus, J. P. and Stute, M. (2021): Widespread six degrees Celsius cooling on land during the Last Glacial Maximum. Nature, 593(7858): 228-232. doi: 10.1038/s41586-021-03467-6

Severinghaus, J. P., Brook, E.J. (1999): Abrupt climate change at the end of the last glacial period inferred from trapped air in polar ice. Science, 286(5441): 930-934. doi: 10.1126/ science.286.5441.930

Severinghaus, J. P., Sowers, T., Brook, E. J., Alley, R. B. and Bender, M. L. (1998): Timing of abrupt climate change at the end of the Younger Dryas interval from thermally fractionated gases in polar ice. Nature, 391(6663): 141-146. doi: 10.1038/34346

Srolovitz, D. J., Anderson, M. P., Grest, G. S. and SAhni, P. S. (1983): Grain growth in two dimensions. Scripta Metallurgica, 17(2): 241-246. doi: 10.1016/0036-9748(83)90106-0

Srolovitz, D. J., Anderson, M. P., SAhni, P. S. and Grest, G. S. (1984): Computer simulation of grain growth - II. Grain size distribution, topology, and local dynamics. Acta Metallurgica, 32(5): 793-802. doi: 10.1016/0001-6160(84)90152-4

Sutton, A. P., Balluffi, R. W. (1995): Interfaces in crystalline materials. Clarendon Press. Materials Park, OH ISBN 0-198513851-2. 